\title{
Sociobiology
}

RESEARCH ARTICLE - BEES

\section{Bee Pollination Highly Improves Oil Quality in Sunflower}

\author{
CAS SILVA, WAC GOdOY, CRO JACOB, G THOMAS, GMS CÂMARA, DA ALVES \\ Luiz de Queiroz College of Agriculture (ESALQ), University of São Paulo, Piracicaba, São Paulo, Brazil
}

\author{
Article History

\section{Edited by} \\ Solange Augusto, UFU, Brazil \\ Received \\ 25 April 2018 \\ Initial acceptance \\ Final acceptance \\ 11 June 2018 \\ 18 August 2018 \\ Publication date \\ 11 October 2018

\section{Keywords} \\ Native bees, crop pollination, nutritional \\ value, vitamin E, Helianthus annuus, Brazil. \\ Corresponding author \\ Denise Araujo Alves \\ Department of Entomology and Acarology \\ Luiz de Queiroz College of Agriculture \\ University of São Paulo \\ Avenida Pádua Dias no 11 \\ CEP 13418-900, Piracicaba-SP, Brasil. \\ E-Mail: daalves@usp.br
}

\begin{abstract}
Sunflower is a pollinator-dependent crop and one of the most cultivated oilseeds in the world, supporting important sectors of the agricultural industry, such as the food supply, because it is an important source of vitamin $E$ and unsaturated fatty acids for human health. Although it is well established that bee pollination improves sunflower seed set, it is still unknown if pollinators influence the nutritional composition. Considering the economic importance of sunflowers for several Brazilian agricultural sectors, the aim of this study was to evaluate the effect of the bee community for (1) achene quality (weight and nutritional composition) and (2) market value. Exclusion experiments were performed with hybrid sunflowers and showed that bee pollination enhanced the achene weight by $91 \%$, the levels of vitamin $\mathrm{E}$ by $45 \%$ and unsaturated fatty acids by $0.3 \%$. Also, it was estimated that due to the pollination services provided by bees, the grower of the sunflower cultivar used in this study nearly duplicates the sale value of the achenes per hectare of cultivated area. Thus, the current study highlights the importance of bees as providers of cross- and self-pollination to nutritional quality of sunflower achenes and provides useful baseline figures to further evaluations of the effects of pollinators on human diets and health.
\end{abstract}

\section{Introduction}

Recently, the global population surpassed 7 billion people, and according to the United Nations projections for 2050, it will reach 9.8 billion (UN, 2017). This fast population growth has imposed significant challenges to meet considerably high demand for food production (Godfray et al., 2010), including the expansion of agricultural lands, which contributes to the loss of biodiversity and its valuable ecosystem services (Steffan-Dewenter et al., 2005). Among all the ecosystem services directly connected to agriculture, animal-mediated pollination is one of them, increasing the production of $75 \%$ of important crops worldwide for balanced human diet (Klein et al., 2007).

Up to $90 \%$ of these leading global crops rely to some degree on pollination provided by bees, improving seed and fruit yield and quality (Klein et al., 2007; Potts et al., 2016). Many crops have a positive relation between fruit set and pollinator richness and abundance (Garibaldi et al., 2013) and bee pollination leads to heavier fruits, with less malformations and higher commercial grades (i.e., increased fruit color, firmness and shelf life; Klatt et al., 2014). Also pollinatordependent crops are important sources of macro- and micronutrients, which are essential for human health (Eilers et al., 2011). Beyond human food supply, bee-pollinated crops contribute to green manure, medicines, fibers and biofuels (Potts et al., 2016). This ecosystem service, which is still disregarded in national and international agricultural policies, contributes to $35 \%$ of global crop production (Klein et al., 2007) and its economic value is estimated at US\$ 235-577 billion annually (Potts et al., 2016). Bees as crop pollinators are thus inextricably intertwined to food and nutritional safety, diversity and stability in the sale prices of agricultural products (Steffan-Dewenter et al., 2005).

Among over 20,000 described bee species (Ascher \& Pickering, 2018), Apis mellifera L. is the most commonly managed bee in the world to enhance agricultural production. However, since A. mellifera is not an effective pollinator of 
many plants, its integrated management with wild bee species substantially increases the crop yields as well as farmers' profits, and at the same time, it preserves biodiversity and the provision of multiple ecosystem services (Garibaldi et al., 2013; Isaacs et al., 2017). Even though A. mellifera is the most abundant sunflower visitor (Free, 1993; Parker, 1981; Carvalheiro et al., 2011), wild native bees species contribute significantly to seed set (Greenleaf \& Kremen, 2006; Carvalheiro et al., 2011). Moreover, bee pollination also enhances the sunflower seed quality, rendering heavier seeds with higher oil contents (Parker, 1981). Even modern sunflower hybrids with high levels of self-compatibility benefit from pollination provided bees (Degrandi-Hoffman \& Chambers, 2006), since their visits are important to transfer pollen from male-phase to female-phase florets of the same flower head or of different plants (McGregor, 1976; Free, 1993).

Sunflower (Helianthus annuus L.) is one of the most cultivated oilseed crops in the world since it supports important sectors of the agricultural industry, such as biofuel, rotation crops, cattle fodder and human food supply. The oil extracted from the sunflower seeds has high nutritional value since it is rich in fatty acids, such as oleic (omega-9) and linoleic (omega-6) acids, vitamin E (including alpha, beta- and gamma-tocopherol) and phytosterols (FAO/WHO, 2015). Although Brazil does not stand out as the main sunflower producers in the world, the national seed yield increased 155\% between 2005 and 2015 (IBGE, 2017). Since sunflowers are highly pollinator-dependent crops, almost of $65 \%$ of the annual agricultural income of this crop (US\$ 41 million) corresponds to the pollination mediated mostly by bees in Brazil (Giannini et al., 2015).

Combined with the Brazilian climatic conditions, the expansion in sunflower productivity is benefited by the high number of bee species, being that Brazil is the second country with greater bee richness worldwide (Ascher \& Pickering, 2018). However, projections for the year 2050 show that climate change will reduce the probability of pollinator occurrence, causing a negative impact on $100 \%$ of Brazilian municipalities where sunflowers are grown, and consequently affecting the Brazilian Gross Domestic Product and food security (Giannini et al., 2017). Considering the economic importance of sunflowers for several Brazilian agricultural sectors and bees maximize seed set of several commercial cultivars, our aim was to evaluate the effect of the bee community for (1) achene quality (weight and nutritional composition) and (2) market value.

\section{Material and Methods}

\section{Experimental Design}

The study was carried out at Luiz de Queiroz College of Agriculture, University of São Paulo (Piracicaba, São Paulo State; $22^{\circ} 42^{\prime} 26.70^{\prime \prime}$ S, $47^{\circ} 37^{\prime} 58.54^{\prime \prime}$ W) from October 2015 to February 2016 (hereafter 2015/16), and from October
2016 to February 2017 (2016/17). In October of each year, sunflower seeds (hybrid BRS 323; EMBRAPA, 2013) were sown in five rows, regularly spaced in $0.80 \mathrm{~m}$, in an area of 25 $\mathrm{x} 4.8 \mathrm{~m}$. Four random blocks were made up of eight plots of $2.0 \times 6.25 \mathrm{~m}$, with 50 sunflowers per plot. Sunflower planting experiments were homogeneously designed and set up aiming to avoid any random variation that could prevent analytical comparisons between the data sets. Procedures essentially involved usual soil management (soil mixture, fertilization, irrigation), manual removal of weeds and insect pests and identical experimental timing between sampling time periods.

In each of the four plots, before any floret had opened, white nylon mesh bags ( $1 \mathrm{~mm}$ mesh width) were placed over seven sunflower heads to exclude insect visitors, allowing only self-pollination. For each one of the other four plots, seven sunflower heads were tagged and left open to be accessible to visitors. At the end of the flowering period, the open sunflower heads were also bagged, in order to avoid seed predators, and all sunflower heads ( $\mathrm{n}=56$ heads per period) were left that way up to seed maturation and the achene set was assessed.

\section{Bee visitors of sunflowers}

Each parcel was randomly walked for 5 min, every hour, and all bees found on the sunflower heads were collected with an entomological net. The sampling took place when over $90 \%$ of the sunflowers were blooming, on a sunny day, with temperature higher than $20^{\circ} \mathrm{C}$, between 7:00 a.m. and 4:00 p.m.

Bee richness and difference in the species composition were compared between 2015/16 and 2016/17 (Kindt \& Coe, 2005). Bee diversity was also estimated, using as reference Simpson's index, due to the evidence of dominant species, and consequently, for capturing distribution variance of species abundance. The difference in the species composition was initially estimated using ecological distance matrices, by the Bray-Curtis method, due to the need to consider the influence of the greater abundance differences of species, and also for high discrepancy between the number of individuals of some species, mainly Plebeia droryana (Friese), Tetragonisca angustula (Latreille), and A. mellifera. The ecological distance was also estimated by Hellinger distance estimation, which takes into account the difference in the proportion of species, most importantly for considering species with low abundance. For this reason, the decision was to show the results only for this analysis. The distance matrix varies from 0 (complete similarity in the species composition between the two periods) to 1 (complete dissimilarity). Due to the variation in the magnitude of abundance values for some species, the ecological distance matrices were analyzed taking into account the following scenarios: (1) all bee species; (2) solitary bees; (3) highly eusocial bees (A. mellifera and stingless bees); (4) highly eusocial bees, excluding the most abundant species, $P$. droryana, or T. angustula or A. mellifera. The analyses were performed using R package BiodiversityR (Kindt, 2016). 
Achene quality and market value

In January of 2015 and 2016, 56 sunflower heads were cut (28 bagged and 28 unbagged sunflower heads), dried at room temperature, and threshed by hand after which the achenes were obtained. For each plot, 1,000 achenes were randomly weighed.

In order to evaluate nutritional quality, $500 \mathrm{~g}$ achenes for each group of sunflower heads were sent to Food Technology Institute (Instituto de Tecnologia de Alimentos - ITAL; Campinas, São Paulo State), where they were submitted to a cold pressing process for oil extraction and identification of tocopherols and fatty acids, using methods of the American Oil Chemists' Society (AOCS). To distinguish methyl esters from fatty acids (saturated, mono- and polyunsaturated), the samples were submitted to preparation according to Hartman and Lago (1973), with adaptations by Firestone (2014). Gas chromatography analyses (Agilent Technologies, model 7890A) were performed with a flame ionization detector. After saponification and esterification, the samples were diluted in hexane and agitated for phase separation, supernatant was collected, transferred to vial $(2 \mathrm{ml})$ and injected into the chromatograph. The compounds were separated in fused silica capillary column CP-Sil $88(100 \mathrm{~m} \times 0.25 \mathrm{~mm} \times 0.20 \mathrm{~mm})$. The column temperature programming started at $130{ }^{\circ} \mathrm{C}$ for $2 \mathrm{~min}$., increased at a rate of $10^{\circ} \mathrm{C} \cdot \mathrm{min}^{-1}$ up to $230^{\circ} \mathrm{C}$, and was kept in isotherm for $20 \mathrm{~min}$. The temperatures used in the injector and in the detector were 230 and $260{ }^{\circ} \mathrm{C}$, respectively. A volume of $1 \mu \mathrm{l}$ of each sample was injected, adopting a splitter ratio of 1:75. The velocity of the hydrogen carrier gas was $30 \mathrm{ml} . \mathrm{min}^{-1}$.

The fatty acids were identified through a comparison in retention time of pure standards of methyl esters of fatty acids with the compounds separated from the samples. The quantification was performed by area normalization (\%) and the results were shown in $\mathrm{g} / 100 \mathrm{~g}$ of samples. The detection and quantification of tocopherols (alpha, beta and gamma) were performed in equipment for liquid chromatography (Prominence LC-20A) attached to a fluorescence detector RF10AXL (Shimadzu) using the excitation wavelength at 292 $\mathrm{nm}$, and emission at $336 \mathrm{~nm} .0 .50 \mathrm{~g}$ of oil diluted in $n$-hexane was weighed. The analytes were separated in a LiChrospher Si 60 normal phase column $(12.5 \mathrm{~cm}$ in length $\mathrm{x} 4 \mathrm{~mm}$ in d.i., and particles of $5 \mu \mathrm{m}$, Merck), having as mobile phase a mixture with $97.6 \%$ of $n$-hexane, $1.8 \%$ de ethyl acetate, and $0.6 \%$ acetic acid, using an isocratic system. The quantification was performed by means of an external standard, using Tocopherol set standard (article 613424, Calbiochem).

For the calculation of market value of achenes, it was assumed that (1) each sunflower head contained 1,000 fertile florets (Pisanty et al., 2014), (2) 40,000 sunflowers were evenly spaced out, in a 1 ha area, as in this study, (3) weights of the 1,000 achenes from bagged and unbagged sunflower heads, and at (4) a sale price in the Unites States (US\$379.00/t of achenes (established in March 2017 by National Supply Company; CONAB, 2017).
Results

\section{Bee community}

In total, 653 individuals belonging to 20 species of 18 bee genera were sampled (Table 1). Apidae was the most representative family, with 574 bees of 13 species (Table 1), which corresponded to $87.9 \%$ of the total number of bees. The second sampled family was Halictidae, with 79 bees from seven species (Table 1).

Augochloropsis cupreola (Cockerell), Bombus morio (Swederus), Diadasina sp., Friesella schrottkyi (Friese), Neocorynura codion (Vachal), Pseudaugochlora graminea (Fabricius), Tetragona clavipes (Fabricius) were sampled exclusively in $2015 / 16$, and represented $50 \%$ of the 18 species (Table 1). The highly eusocial species, A. mellifera e $T$. clavipes, exhibited the highest frequency of individuals (36.47\% and 27.65\%, respectively). In 2016/17, Geotrigona subterranea (Friese) and Melipona quadrifasciata Lepeletier were collected exclusively during this period and corresponded to $18.18 \%$ of the 11 captured species, out of which, the stingless bees $P$. droryana were the most abundant, with $49.07 \%$ of the sampled individuals (Table 1).

Species richness and the Simpson index showed values slightly lower in second period: 18 and 0.77 in 2015/16, and 11 and 0.71 in 2016/17. However, general abundance increased substantially, resulting from 170 individuals in 2015/16 to 483 in 2016/17. The significant increase in overall abundance of bees may be explained by the dominance of some species, especially in 2016/17, when 237 individuals of $P$. droryana, 69 of $T$. angustula, 57 of $A$. mellifera visited sunflower heads.

On the whole, observing Hellinger ecological distance, there was a general tendency for low matrix value $(0.42)$, showing increase in similarity in diversity patterns between 2015/16 and 2016/2017. When the analyzed scenarios in a comparative way were evaluated, highly eusocial bees showed matrix value $(0.46)$ very close to the value obtained for the bees in total $(0.42)$, which suggests that similarity patterns between the periods were determined by the eusocial species, probably due to the high abundance of some of them, as mentioned previously. When the investigated scenario was composed only by solitary bees, there was a decrease in the matrix value $(0.33)$ when compared to the value found for eusocial bees $(0.46)$. This may indicate that, when the proportion of species with low abundance is considered, the solitary species leaned towards similarity more than the eusocial bees. When the three most abundant eusocial bees were considered, the removal of $P$. droryana resulted in the lowest matrix value $(0.28)$ of all scenarios (without $T$. angustula: 0.51 ; without $A$. mellifera: 0.52 ), suggesting that its removal indicated higher tendency to similarity between 2015/16 and 2016/17. Therefore, the scenarios that indicated the highest similarity in the species composition between the two periods were the one with the removal of $P$. droryana from the eusocial species, and the one with solitary bees. 
Table 1. Bee species and respective number of individuals sampled with entomological net in sunflower areas in 2015/16 and 2016/17.

\begin{tabular}{|c|c|c|c|c|}
\hline \multirow{2}{*}{ Family } & \multirow{2}{*}{ Tribe } & \multirow{2}{*}{ Species } & \multicolumn{2}{|c|}{ Number of bees } \\
\hline & & & 2015/16 & 2016/17 \\
\hline \multirow[t]{8}{*}{ Apidae } & Apini & Apis mellifera Linnaeus, 1758 & 62 & 57 \\
\hline & Ceratinini & Ceratina sp. & 1 & 0 \\
\hline & Emphorini & Diadasina sp. & 3 & 0 \\
\hline & Meliponini & Friesella schrottkyi (Friese, 1900) & 1 & 0 \\
\hline & & Geotrigona subterranea (Friese, 1901) & 0 & 6 \\
\hline & & Melipona quadrifasciata Lepeletier, 1836 & 0 & 1 \\
\hline & & Nannotrigona testaceicornis (Lepeletier, 1836) & 3 & 25 \\
\hline & & Plebeia droryana (Friese, 1900) & 5 & 237 \\
\hline \multirow[t]{7}{*}{ Halictidae } & Augochlorini & Augochlora (Augochlora) esox (Vachal, 1911) & 18 & 5 \\
\hline & & Augochlora (Oxystoglossella) morrae Strand, 1910 & 3 & 14 \\
\hline & & Augochlora sp. & 2 & 32 \\
\hline & & Augochloropsis cupreola (Cockerell, 1900) & 2 & 0 \\
\hline & & Neocorynura codion (Vachal, 1904) & 1 & 0 \\
\hline & & Pseudaugochlora graminea (Fabricius, 1804) & 1 & 0 \\
\hline & Halictini & Dialictus creusa (Schrottky, 1910) & 1 & 0 \\
\hline Total & & & 170 & 483 \\
\hline
\end{tabular}

Achene quality and market value

The mean weight of achenes of unbagged sunflowers (mean \pm s.d.: $74.27 \pm 7.35 \mathrm{~g}$ ) was substantially higher than those of bagged sunflowers $(38.82 \pm 10.27 \mathrm{~g})(\mathrm{t}=-7.9388$; $\mathrm{p}=0.000003)$. Then, the flower visitors contributed with the increase in the mean weight of the achenes by $91.3 \%$. When the periods were considered separately, the achenes of unbagged sunflowers in 2015/16 were $107.35 \%$ heavier than the bagged ones $(\mathrm{t}=-8.4938 ; \mathrm{p}=0.002762)$, while this weight difference was $79.72 \%$ for $2016 / 17(t=-7.7933 ; p=0.002395$; Fig 1$)$.

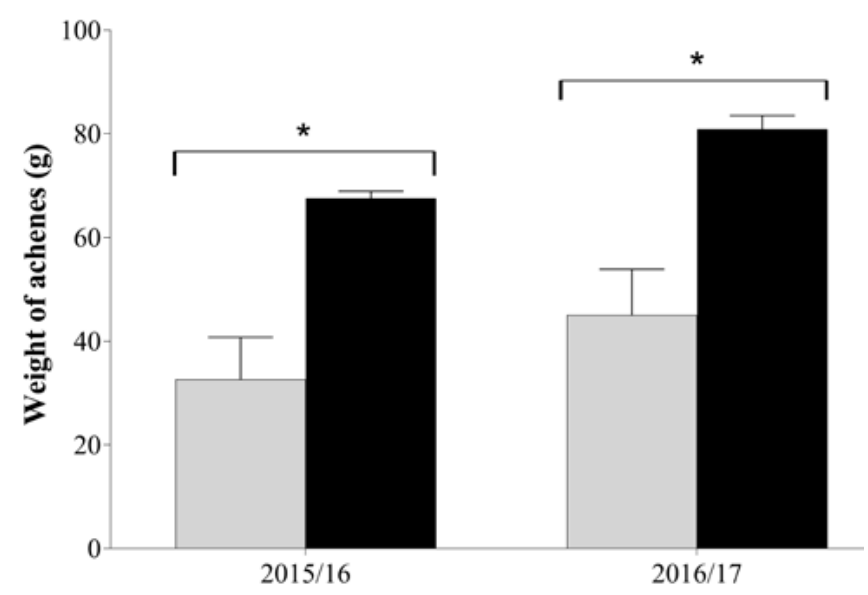

Fig 1. Mean weight ( \pm s.d.) of 1,000 achenes of unbagged (grey) and bagged (black) sunflower heads in 2015/16 and 2016/17. * t test, p $<0.005$.
For each cultivated hectare, the estimated sale price of the achenes of bagged sunflowers was US\$ 588.51, while unbagged sunflowers resulted in the estimate of US\$ 1,125.93. Then, the pollinators increased the sale price of sunflower achenes by $91.3 \%$.

Considering the nutritional value of sunflower oil, the levels of unsaturated fatty acids were higher than the saturated ones, predominating the oleic acid (omega-9) among the monounsaturated, and the linoleic acid (omega-6) among the polyunsaturates (Table 2). The alpha-tocopherol was highly predominant among the other tocopherols (Table 2).

In 2015/16, since most of the achenes of the bagged sunflowers were empty (when pollination fails, the floret results in an empty achene), it was not possible to extract oil for chemical analysis. With respect to unbagged sunflowers in the same period, $23 \%$ of the $500 \mathrm{~g}$ of achenes corresponded to lipids. Among the tocopherols, the alpha-tocopherol corresponded to $96.34 \%$, followed by the beta- and gammatocopherol, $2.22 \%$ and $1.44 \%$, respectively. Concerning the fatty acids, omega-9 corresponded to $99.46 \%$ of the monounsaturates, omega- 6 to $100 \%$ of the polyunsaturates, and the palmitic and stearic acids, at $51.69 \%$ and $32.77 \%$ of the saturates, respectively (Table 3). In 2016/17, the oil of unbagged sunflowers had higher levels of gamma- (160.71\%), beta- $(54.90 \%)$ and alpha-tocopherol $(40.06 \%)$, and linolenic (omega-3; 13.33\%), behenic $(9.88 \%)$, lignoceric $(7.14 \%)$, arachidic (4.17\%), stearic (4.05\%) and linoleic (3.83\%) acids, 
Table 2. Nutrients that were quantified in oil from achenes of unbagged and bagged sunflower heads in $2015 / 16$ and $2016 / 17$.

\begin{tabular}{lllll}
\hline \multirow{2}{*}{ Components } & \multicolumn{2}{c}{$\mathbf{2 0 1 5 / 1 6}$} & \multicolumn{2}{c}{$\mathbf{2 0 1 6 / 1 7}$} \\
& unbagged & bagged & unbagged & bagged \\
\hline $\begin{array}{l}\text { Tocopherols }(\mathrm{mg} / \mathrm{l00g}) \\
\text { alpha-tocopherol }\end{array}$ & 57.68 & - & 40.66 & 29.03 \\
beta-tocopherol & 1.33 & - & 0.79 & 0.51 \\
gamma-tocopherol & 0.86 & - & 2.92 & 1.12 \\
Fatty acids (g/l00g) & & & & \\
$\quad$ saturated & 8.30 & & 8.77 & 8.70 \\
monounsaturated & 47.89 & - & 51.44 & 52.53 \\
polyunsaturated & 39.42 & - & 35.39 & 34.07 \\
Composition offatty acid (g/lo0g) & & & & \\
palmitic & 4.29 & - & 4.25 & 4.34 \\
palmitoleic (omega-7) & 0.10 & - & 0.10 & 0.11 \\
stearic & 2.72 & - & 3.08 & 2.96 \\
oleic (omega-9) & 47.63 & - & 51.35 & 52.27 \\
linoleic (omega-6) & 39.42 & - & 35.22 & 33.92 \\
arachidic & 0.22 & - & 0.25 & 0.24 \\
linolenic (omega-3) & 0.00 & - & 0.17 & 0.15 \\
behenic & 0.78 & - & 0.89 & 0.81 \\
lignoceric & 0.29 & - & 0.30 & 0.28 \\
\hline
\end{tabular}

compared with oil of bagged sunflowers in the same period. However, there was a decrease in the levels of palmitic (2.07\%), palmitoleic (omega-7; 9.09\%) and oleic (1.76\%) acids (Table 2).

\section{Discussion}

This study shows that pollinators play an essential role for improving achene quality and thus market value in hybrid sunflowers. Even though there are efforts for the development of hybrid sunflower cultivars that display high levels of selfcompatibility and are less dependent on cross-pollination, but surprisingly enough, pollinators contributed with an increase of $91 \%$ in the achene weight and in the increase of the levels of some fatty acids, and specially, of tocopherols in the oil.

Even in a small area of sunflower cultivation $\left(100 \mathrm{~m}^{2}\right)$, a high number of bee species was recorded, corroborating previous studies carried out in Brazil (Morgado et al., 2002), United States (Parker, 1981; Greenleaf \& Kremen, 2006), Spain (Hevia et al., 2016) and South Africa (Carvalheiro et al., 2011). Taking into account the 20 species sampled in sunflower heads, $50 \%$ were highly eusocial species. These species were dominant flower visitors, and the native stingless bees ( $P$. droryana, $T$. clavipes e $T$. angustula) and the exotic A. mellifera corresponded to $56.4 \%$ and $18.3 \%$ of the individuals, respectively. The dominance of highly eusocial bees was expected since their perennial colonies consist of one egg-laying queen and a large worker population (e.g., $A$. mellifera: tens of thousands of workers (Michener, 1974); $P$. droryana: 3,000 workers; T. clavipes: 7,000 workers;
T. angustula: 5,000 workers (Tóth et al., 2004)) that need constant nutritional supply to ensure their survival, especially during periods of floral resource scarcity (Maia-Silva et al., 2016). Thus, there are a diversity of foraging strategies and signals used by bees to guide their nestmates to rich food sources (Jarau \& Hrncir, 2009), as they need a constant supply of nectar and pollen that are obtained from a wide range of plant species (Kleinert et al., 2009).

Sunflower is a highly attractive source of nectar and pollen to bees (Parker, 1981), specially to stingless bees. Due to their biological and behavioral characteristics previously mentioned, they are ecologically dominant in comparison to the other native flower visitors in the Neotropical region (Roubik, 1989). During 2015/16, T. clavipes was the most dominant native species, whereas $P$. droryana showed greater abundance among the flower visitors in the second period. When $P$. droryana was removed from the group of highly eusocial bees with respect to Hellinger distance analysis, the species composition of this group was more similar taking into account the two periods. This result, as the one obtained for analysis with solitary bees, showed that high abundance of few species may influence negatively the general diversity of bee species, since both species richness and diversity had slight declines between the two periods.

However, the expressive increase in the mean weight of the achenes, with $67.64 \mathrm{~g}$ in $2015 / 16$ and $80.90 \mathrm{~g}$ in 2016/17, may be in part attributed to the increase in the overall bee abundance. Even if the community of flower visitors was composed of several taxa, the pollinating efficiency of bees 
on a given crop depends on their behavior on the flowers and on the probability of transferring pollen from their bodies to the flower stigmas of conspecific plants (Woodcock et al., 2013). Even though A. mellifera is the most abundant flower visitor of several animal-pollinated crops, including sunflowers (Carvalheiro et al., 2011; Morgado et al., 2002; Greenleaf \& Kremen, 2006), crop productivity increases substantially with pollination services provided by wild native insects (Garibaldi et al., 2013). The results obtained in this study are consistent with previous studies, suggesting that native flower visitors interact effectively with crops and contribute significantly to pollination and yield of most crops regardless of A. mellifera abundance (Garibaldi et al., 2013), reaffirming that the abundance of wild native bees is relevant for crop stability (Garibaldi et al., 2011).

Higher flower-visitor density could increase crop yields by a median of $24 \%$ in fields with less than 2 hectares, which are very common in developing countries such as Brazil, enhancing therefore small farmer livelihoods (Garibaldi et al., 2016). Taking into account that, due to the pollination services provided by bees, the growers of the sunflower cultivar used in this study nearly duplicate the sale value of the achenes per hectare of cultivated area, the restoration and conservation of habitats for wild pollinators, including floral resources and nesting sites, within agricultural landscape enhance biodiversity and the ecosystem services it provides (Garibaldi et al., 2011; Wratten et al., 2012).

Pollinators enhanced, besides achene weight, sunflower oil composition. The oil from achenes of unbagged sunflowers presented an increase of $44.7 \%$ of total tocopherols when compared to the oil of flowers in which pollinators had been excluded. Tocopherols and tocotrienols compose the vitamin $\mathrm{E}$ family, which is considered the most important antioxidant in human diet (Mathur et al., 2015), and a large portion is present in pollinator-mediated crops (alpha-: $36 \%$ of crops; beta-: $99 \%$; gamma-tocopherol: $67 \%$, Eilers et al., 2011). Among the tocopherols found in sunflower oil, alphatocopherol constitutes the largest portion, and increased $40.1 \%$ in unbagged sunflowers. However, gamma-tocopherol showed a substantial increase of $160.7 \%$. Even though alphatocopherol is the most known analog in vitamin E, more recent studies suggest that gamma-tocopherol show more potent antioxidant, cardioprotective and anti-inflammatory effects than alpha-tocopherol (reviewed in Mathur et al., 2015).

In relation to the fatty acids present in sunflower oil, slight difference between unbagged and bagged sunflowers was detected, contrary to the findings concerning tocopherols. Among the polyunsaturated fatty acids, omega- 6 level was $3.8 \%$ higher in achenes of unbagged sunflowers. Although omega-3 level is extremely lower than omega- 6 level, the pollinators affected the former by $13.3 \%$. Concerning the saturated acids, they composed less than $10 \%$ of fatty acids, the oil of unbagged sunflowers showed slightly lower levels of palmitic acid and a little higher level of stearic acid than bagged sunflowers. Since sunflower oils with high contents of omega-9 (monounsaturated acid) and omega-6 (polyunsaturated acid) and low levels saturated acids, strategies have been implemented for the development of sunflower cultivars with these characteristics (Raß et al., 2008), such is the case of hybrid BRS 323 used in this study. Oils with higher omega-9 than omega- 6 contents showed increased level of oxidative stability, which is desirable for frying, refining and storage purposes, and also, better dietetic properties since it reduces cholesterol in blood (Flagella et al., 2002). However, the same sunflower cultivar may show difference in fatty acid levels depending on environmental conditions, such as temperature, light and water availability, and on sowing period (Flagella et al., 2002).

Similar to this study, pollinators improved the nutritional composition of fruits and seeds of several globally important crops. For example, insect pollinators, particularly bees, influenced the chlorophyll content in oilseed rape (Brassica napus, Bommarco et al., 2012), the proportions of oleic to linoleic acid in almond (Prunus dulcis, Brittain et al., 2014) and the sugar-acid-ratio in strawberry (Fragaria $x$ ananassa, Klatt et al., 2014). Thus, the current study highlights the importance of bees as providers of cross- and self-pollination to nutritional quality and market value of sunflower achenes and provides useful baseline figures to further evaluations of the effects of pollinators on human diets and health (Eilers et al., 2011; Potts et al., 2016).

\section{Acknowledgements}

We are especially thankful to Eduardo A. B. Almeida (FFCLRP-USP) for bee identification, Roberto Gaioski Jr, Marcela M. Barbosa and Samanta L. Nanzer for field assistance and José B. Malaquias for assisting in experimental design. This study was financed in part by the Coordenação de Aperfeiçoamento de Pessoal de Nível Superior - Brasil (CAPES) - Finance Code 001and Associação Brasileira de Estudo das Abelhas (A.B.E.L.H.A.).

\section{Authors' Contribution}

Conceived and designed the experiment: CASS, GMSC. Performed the experiment: CASS, CROJ. Analyzed the data: WACG, GT. Interpreted the data: DAA, WACG, CASS, CROJ. Wrote the paper: DAA, WACG, CASS. All authors read and approved the final manuscript.

\section{References}

Ascher, J.S. \& Pickering, J. (2018). Discover life: bee species guide and world checklist (Hymenoptera: Apoidea: Anthophila). $\mathrm{http}: / /$ www.discoverlife.org $/ \mathrm{mp} / 20 \mathrm{q}$ ?guide=Apoidea_species \&flags=HAS. Accessed 08 April, 2018

Bommarco, R., Marini, L. \& Vaissière, B.E. (2012). Insect pollination enhances seed yield, quality, and market value 
in oilseed rape. Oecologia, 169: 1025-1032. doi: 10.1007/ s00442-012-2271-6

Brittain, C., Kremen, C., Garber, A. \& Klein, A.-M. (2014). Pollination and plant resources change the nutritional quality of almonds for human health. PloS ONE, 9: e90082. doi: 10.1371/journal.pone.0090082

Carvalheiro, L.G., Veldtman, R., Shenkute, A.G., Tesfay, G.B., Pirk, C.W.W., Donaldson, J. S. \& Nicolson, S.W. (2011). Natural and within-farmland biodiversity enhances crop productivity. Ecology Letters, 14: 251-259. doi: 10.1111/ j.1461-0248.2010.01579.x

CONAB (2017). Conjuntura Mensal - Girassol. http://www.conab. gov.br/OlalaCMS/uploads/arquivos/17_04_10_10_06_42_ girassol_-_conjuntura_mensal_-_marco_de_2017.pdf Accessed 20 June, 2017

Degrandi-Hoffman, G. \& Chambers, M. (2006). Effects of honey bee (Hymenoptera: Apidae) foraging on seed set in self-fertile sunflowers (Helianthus annuus L). Environmental Entomology, 35: 1103-1108. doi: 10.1603/0046-225X-35.4.1103

Eilers, E.J., Kremen, C., Greenleaf, S.S., Garber, A.K. \& Klein, A.-M. (2011). Contribution of pollinator-mediated crops to nutrients in the human food supply. PLoS ONE, 6: e21363. doi: 10.1371/journal.pone.0021363

EMBRAPA (2013). Girassol. https://www.embrapa.br/buscade-solucoes-tecnologicas/-/produto-servico/918/girassol--brs-323. Accessed 15 June, 2017

FAO/WHO (2015). Codex Standards for Named Vegetable Oils. CODEX-STAN 210 - 1999 (Amended 2005, 2011, 2013, 2015). http://www.fao.org/docrep/004/y2774e/y2774e04.htm. Accessed 21 February, 2018

Firestone, D. (2014). Official Method Ce 1a-13 e Ce 1h-05. Official methods and recommended practices of the AOCS. Illinois: AOCS Pressp

Flagella, Z., Rotunno, T., Tarantino, E., Di Caterina, R. \& De Caro, A. (2002). Changes in seed yield and oil fatty acid composition of high oleic sunflower (Helianthus annuus L.) hybrids in relation to the sowing date and the water regime. European Journal of Agronomy, 17: 221-230. doi: 10.1016/ S1161-0301(02)00012-6

Free, J.B. (1993). Insect pollination of crops. London: Academic Press, $684 \mathrm{p}$

Garibaldi, L.A., Carvalheiro, L.G., Vaissière, B.E., GemmillHerren, B., Hipólito, J., Freitas, B.M., Ngo, H.T., Azzu, N., Sáez, A. \& Åström, J. (2016). Mutually beneficial pollinator diversity and crop yield outcomes in small and large farms. Science, 351: 388-391. doi: 10.1126/science.aac7287

Garibaldi, L.A., Steffan-Dewenter, I., Kremen, C., Morales, J.M., Bommarco, R., Cunningham, S.A., Carvalheiro, L.G., Chacoff, N.P., Dudenhoeffer, J.H. \& Greenleaf, S.S. (2011).
Stability of pollination services decreases with isolation from natural areas despite honey bee visits. Ecology Letters, 14: 1062-1072. doi: 10.1111/j.1461-0248.2011.01669.x

Garibaldi, L.A., Steffan-Dewenter, I., Winfree, R., Aizen, M.A., Bommarco, R., Cunningham, S.A., Kremen, C., Carvalheiro, L.G., Harder, L.D., Afik, O., Bartomeus, I., Benjamin, F., Boreux, V., Cariveau, D., Chacoff, N.P., Dudenhöffer, J.H., Freitas, B.M., Ghazoul, J., Greenleaf, S., Hipólito, J., Holzschuh, A., Howlett, B., Isaacs, R., Javorek, S.K., Kennedy, C.M., Krewenka, K., Krishnan, S., Mandelik, Y., Mayfield, M.M., Motzke, I., Munyuli, T., Nault, B.A., Otieno, M., Petersen, J., Pisanty, G., Potts, S.G., Rader, R., Ricketts, T.H., Rundlöf, M., Seymour, C.L., Schüepp, C., Szentgyörgyi, H., Taki, H., Tscharntke, T., Vergara, C. H., Viana, B.F., Wanger, T.C., Westphal, C., Williams, N. \& Klein, A.M. (2013). Wild pollinators enhance fruit set of crops regardless of honey bee abundance. Science, 339: 16081611. doi: $10.1126 /$ science. 1230200

Giannini, T.C., Cordeiro, G.D., Freitas, B.M., Saraiva, A. M. \& Imperatriz-Fonseca, V.L. (2015). The dependence of crops for pollinators and the economic value of pollination in Brazil. Journal of Economic Entomology, 108: 849-857. doi: 10.1093/jee/tov093

Giannini, T.C., Costa, W.F., Cordeiro, G.D., ImperatrizFonseca, V.L., Saraiva, A.M., Biesmeijer, J. \& Garibaldi, L.A. (2017). Projected climate change threatens pollinators and crop production in Brazil. PloS ONE, 12: e0182274. doi: 10.1371/journal.pone.0182274

Godfray, H.C.J., Beddington, J.R., Crute, I.R., Haddad, L., Lawrence, D., Muir, J.F., Pretty, J., Robinson, S., Thomas, S.M. \& Toulmin, C. (2010). Food security: the challenge of feeding 9 billion people. Science, 327: 812-818. doi: 10.1126/ science. 1185383

Greenleaf, S.S. \& Kremen, C. (2006). Wild bees enhance honey bees' pollination of hybrid sunflower. Proceedings of the National Academy of Sciences, USA, 103: 13890-13895. doi: 10.1073/pnas.0600929103

Hartman, L. \& Lago, R. (1973). Rapid preparation of fatty acid methyl esters from lipids. Laboratory Practice, 22: 475-756

Hevia, V., Bosch, J., Azcárate, F.M., Fernández, E., Rodrigo, A., Barril-Graells, H. \& González, J.A. (2016). Bee diversity and abundance in a livestock drove road and its impact on pollination and seed set in adjacent sunflower fields. Agriculture, Ecosystems \& Environment, 232: 336-344. doi: 10.1016/j.agee.2016.08.021

IBGE (2017). Sistema IBGE de Recuperação Automática SIDRA. https://sidra.ibge.gov.br/home/pimpfbr/brasil. Accessed 11 December 2017

Isaacs, R., Williams, N., Ellis, J., Pitts-Singer, T.L., Bommarco, R. \& Vaughan, M. (2017). Integrated Crop 
Pollination: Combining strategies to ensure stable and sustainable yields of pollination-dependent crops. Basic and Applied Ecology, 22: 44-60. doi: 10.1016/j.baae.2017.07.003

Jarau, S. \& Hrncir, M. (Eds) (2009). Food exploitation by social insects: ecological, behavioral, and theoretical approaches. Boca Raton: CRC Press, Taylor \& Francis Group

Kindt, R. (2016). Package 'BiodiversityR'. http://www.rproject.org. Accessed 02 February, 2018

Kindt, R. \& Coe, R. (2005). Tree diversity analysis: a manual and software for common statistical methods for ecological and biodiversity studies. Nairobi: World Agroforestry Centrep

Klatt, B.K., Holzschuh, A., Westphal, C., Clough, Y., Smit, I., Pawelzik, E. \& Tscharntke, T. (2014). Bee pollination improves crop quality, shelf life and commercial value. Proceedings of the Royal Society B, 281: 20132440. doi: 10.1098/rspb.2013.2440

Klein, A.M., Vaissière, B.E., Cane, J.H., Steffan-Dewenter, I., Cunningham, S.A., Kremen, C. \& Tscharntke, T. (2007). Importance of pollinators in changing landscapes for world crops. Proceedings of the Royal Society B, 274: 303-313. doi: 10.1098/rspb.2006.3721

Kleinert, A.M.P., Ramalho, M., Cortopassi-Laurino, M. \& Imperatriz-Fonseca, V.L. (2009). Abelhas sociais (Bombini, Apini, Meliponini). In A.R. Panizzi \& J.R.P. Parra (Eds.), Bioecologia e nutrição de insetos (pp 371-424). Brasília: EMBRAPA Informação Tecnológica

Maia-Silva, C., Hrncir, M., Imperatriz-Fonseca, V.L. \& Schorkopf, D.L.P. (2016). Stingless bees (Melipona subnitida) adjust brood production rather than foraging activity in response to changes in pollen stores. Journal of Comparative Physiology A, 202: 723-732. doi: 10.1007/ s00359-016-1095-y

Mathur, P., Ding, Z., Saldeen, T. \& Mehta, J.L. (2015). Tocopherols in the prevention and treatment of atherosclerosis and related cardiovascular disease. Clinical Cardiology, 38: 570-576. doi: 10.1002/clc. 22422

McGregor, S.E. (1976). Insect pollination of cultivated crop plants. U.S.D.A. Handbook 496. Washington: U.S. Department of Agriculture, Agricultural Research Servicep

Michener, C.D. (1974). The social behavior of the bees: a comparative study. Massachusetts: Belknap Press of Harvard University Press, $404 \mathrm{p}$
Morgado, L.N., Carvalho, C.F., Souza, B. \& Santana, M.P. (2002). Fauna de abelhas (Hymenoptera: Apoidea) nas flores de girassol Helianthus annuus L. Ciencia e Agrotecnologia, 26: 1167-1177

Parker, F.D. (1981). Sunflower pollination: abundance, diversity and seasonality of bees and their effect on seed yields. Journal of Apicultural Research, 20: 49-61. doi: 10.1080/ 00218839.1981 .11100473

Pisanty, G., Klein, A.-M., Mandelik, Y. (2014). Do wild bees complement honeybee pollination of confection sunflowers in Israel? Apidologie, 45: 235-247. doi: 10.1007/s13592-013-0242-5

Potts, S.G., Imperatriz-Fonseca, V.L., Ngo, H.T., Aizen, M.A., Biesmeijer, J.C., Breeze, T.D., Dicks, L.V., Garibaldi, L.A., Hill, R., Settele, J. \& Vanbergen, A.J. (2016). Safeguarding pollinators and their values to human well-being. Nature, 540: 220-229. doi: 10.1038/nature20588

Raß, M., Schein, C. \& Matthäus, B. (2008). Virgin sunflower oil. European Journal of Lipid Science and Technology, 110: 618-624

Roubik, D.W. (1989). Ecology and natural history of tropical bees. Cambridge Tropical Biology Series. Cambridge: Cambridge University Press, $514 \mathrm{p}$

Steffan-Dewenter, I., Potts, S.G. \& Packer, L. (2005). Pollinator diversity and crop pollination services are at risk. Trends in Ecology \& Evolution, 20: 651-652. doi: 10.1016/j. tree.2005.09.004

Tóth, E., Queller, D.C., Dollin, A. \& Strassmann, J.E. (2004). Conflict over male parentage in stingless bees. Insectes Sociaux, 51: 1-11. doi: 10.1007/s00040-003-0707-z

UN (2017). World Population Prospects: The 2017 Revision, Key Findings and Advance Tables. United Nations, New York

Woodcock, B., Edwards, M., Redhead, J., Meek, W., Nuttall, P., Falk, S., Nowakowski, M. \& Pywell, R. (2013). Crop flower visitation by honeybees, bumblebees and solitary bees: Behavioural differences and diversity responses to landscape. Agriculture, Ecosystems \& Environment, 171: 1-8. doi: 10.10 16/j.agee.2013.03.005

Wratten, S.D., Gillespie, M., Decourtye, A., Mader, E. \& Desneux, N. (2012). Pollinator habitat enhancement: benefits to other ecosystem services. Agriculture, Ecosystems \& Environment, 159: 112-122. doi: 10.1016/j.agee.2012.06.020

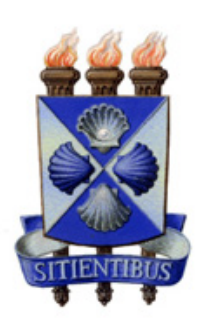

